\title{
Professor Ragunathar Kanagasuntheram
}

Professor Ragunathar Kanagasuntheram died on 19 June 2010, in Adelaide, Australia. He was ninety one. The writer had the previledge and honour of being his pupil in 1956.

Born on 13 October 1919 in Karainagar, he hailed from a family of respected teachers. He matriculated from Jaffna Hindu College, and entered Colombo Medical College in 1938. He qualified as a doctor in 1944 with First Class honours and the Rockwood Gold Medal. In 1948, he was appointed a Lecturer in Anatomy, and shortly thereafter, he left for Cambridge from where he obtained his $\mathrm{PhD}$. He was an accomplished tennis player, and obtained Colours at Cambridge and later the championship of the Tamil Union Sports Club.

'Kanaks' left our shores to Khartoum, where in recognition of outstanding research he was appointed Reader. He subsequently moved to the National
University of Singapore where in 1962 he became Professor of Anatomy, and subsequently Emeritus Professor after retirement in 1980. He was a Member of the Academy of Medicine of Singapore and the Anatomical Society of Great Britain and Ireland, Fellow of the Institute of Biology, London, and Visiting Professor at Flinders University. In 1974, he delivered the Galloway Memorial Lecture to the Anatomical Society of Great Britain, on "Some unresolved mysteries in the design of the visual system".

By a twist of fate 'Kanaks' then returned to the place of his birth, Jaffna, and assumed duties as Professor and later Dean of the Medical Faculty. He was conferred the DSc by the University.

The death of Professor Kanagasuntheram leaves many who knew him saddened, for he was a self made man, a brilliant researcher and a teacher devoted to his students.

Mahasara Gunaratne, Emeritus Professor, University of Peradeniya. 